Sports Training

\title{
Developmental pathway routes to achieve expert performance in portuguese track and field athletes
}

\author{
Eduarda Maria Rocha Teles de Castro Coelho ${ }^{1}$ (D), Flávia Rodrigues da Costa $^{2}$ (D), \\ Nuno Miguel Correia Leite ${ }^{1}$ (D), Sara Diana Leal dos Santos ${ }^{1}$ \\ ${ }^{1}$ Universidade de Trás-os-Montes e Alto Douro, Centro de Investigação em Desporto, Saúde, e \\ Desenvolvimento Humano, Vila Real, Portugal; ${ }^{2}$ Universidade de Trás-os-Montes e Alto Douro, \\ Vila Real, Portugal.
}

Associate Editor: Ricardo Augusto Barbieri. Estácio UniSEB/Ribeirão Preto, SP, Brasil.

\begin{abstract}
Aim: The aim of this study was to characterize the developmental pathway undertaken by Portuguese expert track and field athletes considering the quantity and type of structured and unstructured activities. Methods: The sample was composed of 24 experts and 35 non-expert athletes who completed a questionnaire designed to gather information about their previous experiences in sports. Results: Results reveal key factors which distinguished expert from non-expert athletes' developmental pathway were related to a greater commitment within track and field in relation to years $(\mathrm{U}=251.000, p<0.01)$ and hours $(\mathrm{U}=212.500, p<.01)$, as well as with the number of years spent in unstructured activities $(\mathrm{U}=284.500, p<.05)$. Furthermore, a significant association $\left(\chi^{2}=27.131, p<0.01\right)$ was found between the number of unstructured activities practiced and an expert performance attainment. Conclusions: These findings revealed that more successfully track and field athletes had an early diversified pathway with greater involvement in structured and unstructured activities. Overall, the study provides an insight into the developmental pathway of Portuguese track and field athletes.
\end{abstract}

Keywords athlete development, deliberate practice, diversification, unstructured activities, expertise.

\section{Introduction}

The analysis of long-term athletic development has provided interesting features to promote more sustainable environments that support the athletes' expertise ${ }^{1-4}$. Despite the lack of consensus in the concept of expert sport performance $^{5}$, the available research highlights the playing level attained during the players' sports career as the ultimate criteria $^{6-8}$. Hence, expertise is dependent on several interacting factors incorporated during the sport pathway ${ }^{9,10}$. Accordingly, distinct pathways are usually highlighted in well-established development models ${ }^{8}$. Several theoretical models have been proposed, however, the Developmental Model of Sports Participation (DMSP) is considered more indicated since it provides clear assumptions and practical applications that are aligned with theories of youth development. The DMSP explains athlete development underpinned in three sport trajectories: i) recreational participation through early diversification and deliberate play; ii) elite performance attainment through an early diversification and deliberate play, and iii) elite performance attainment through an early specialization and deliberate practice ${ }^{11,12}$. The early specialization pathway is associated with a commitment to one single sport from a young age and the activities practiced are highly effortful, specific, and structured (i.e., deliberate practice). On the other hand, early diversification includes the involvement in several sports, during the early years of development, in which the activities are less structured (i.e., deliberate play $)^{11,13}$. Indeed, deliberate play promotes fun and enjoyment activities which are proposed to lead to higher intrinsic motivation and possibly prevent an early sport dropout ${ }^{14,15}$. This developmental sport pathway allows the experience of several environments that stimulate physical, cognitive, affective, and psychosocial aspects, as well as promotes a higher movement exploration, which is considered fertile ground to trigger creative behaviours ${ }^{16-18}$

In this vein, one of several criteria used to differentiate the previous pathways are related to the early structure of practice. Thus, the structured sports activities are recognized as formal adult-led practices, including all kinds of organized training and direct instruction, which are intended to lead to explicit learning and skills acquisi$\operatorname{tion}^{19,20}$. On the other hand, unstructured sports activities include informal youth-led activities such as street games (i.e., football and basketball), backyard activities, and school playground play $^{21}$. These types of activities provide an opportunity for children to spend time together and have fun by playing games, which are normally freely 
created and adapted to different environments. The singular form of these activities leads children to create, adapt and negotiate rules, which stimulates the development of important characteristics, such as innovation, creativity, adaptability, and flexibility ${ }^{22-24}$. Considering this line of reasoning, Côté and colleagues ${ }^{11,12}$ suggest a balance between both types of practices, mostly unstructured during early years, with the proportion of structured hours gradually increasing. Despite the evident importance of unstructured activities, little attention has been given to their benefits in athlete development and expertise achievement ${ }^{21}$.

Considering the previous assumptions, researchers have been debating on the benefits of diversified practice and unstructured activities' involvement, during the early years, in the ability to recognise patterns of play and promote skills transfer across sports ${ }^{25-27}$. This possible transfer derived from an early diversification commitment, which may lead to greater learning and adaptive ratings displayed by the athletes in advanced sports requirements. Accordingly, Santos and collaborators ${ }^{28}$ research intended to understand the magnitude of the effects of a specific training program on the development of motor, technical and tactical skills when accounting with different sport pathways (specialized or diversified). Results revealed that early diversification displays the most significant benefits when compared to the specialization path, providing evidence of how sports experiences affect skill acquisition in adulthood. Furthermore, Güllich's study ${ }^{29}$ emphasizes the early diversified practice benefits in learning experiences and the boost of long-term acquisition among international medallists. Evidence has demonstrated that early diversification can lead to expert performance and also provide additional outcomes, such as a higher likelihood for continued sport participation during one's lifespan and a more well-sustained personal development ${ }^{30-33}$. Alternatively, there is a growing concern that early specialization may lead to dropout or burnout of sports practice ${ }^{34,35}$, as well as the athletes' propensity for injuries is higher due to excessive movement repetition ${ }^{32,36,37}$.

In this line of reasoning, as supported by the European Athletics Report ${ }^{38}$ the youth Portuguese track and field athletes' background are commonly enrooted in several disciplines related to athletics before their specialization. Portuguese Athletics Federation has enjoyed relative success in youth programs and many talented athletes have emerged from the ranks. Hence, there is a need to specifically explore the previous sports experiences and training structure of Portuguese track and field athletes towards to better understand the integrated factors that contribute to their development. Using retrospective methodologies in this type of research have contributed to important advances in the field ${ }^{39}$. Thus, understanding the developmental activities of expert and non-expert Portuguese track and field athletes will reinforce the con- sistency and robust findings within the very top margin of the success continuum. Consequently, this study aimed to characterize the developmental pathway undertaken by expert Portuguese track and field athletes considering the quantity and type of structured and unstructured activities. Based on theoretical evidence, it was expected that experts spent more time on structured and unstructured activities, compared to the non-expert track and field athletes.

\section{Method}

\section{Participants}

The sample was composed of fifty-nine Portuguese male and female Track and Field athletes who participated in the 2014, 2015, and/or 2016 National Championships. The non-expert group was composed of thirteen female and twenty-two male participants $(\mathrm{n}=35$; age: $21.8 \pm$ 2.5 years old; $5.5 \pm 2.2$ years of experience) included athletes who never reached the first eight places in these competitions and the expert group composed of 13 female and 11 male participants $(n=24 ; 24.5 \pm 3.3$ years old; 7.6 \pm 3.2 years of experience) was composed of 24 athletes who reached the podium, at least twice, between 20142016 National Championships at the time of data collection. Thus, the main criteria used to select the athletes were related to the place obtained in several National Championships. Participants received a clear explanation of the nature and the demands of the study and completed an informed consent prior to testing. The study protocol was approved and followed the guidelines stated by the local Institutional Research Ethics Committee (UID/DTP/ 04045/2019) and according to the recommendations of the Declaration of Helsinki.

\section{Procedures}

In order to examine the sports path of Portuguese track and field athletes, the procedure included an adapted questionnaire designed to collect information on the acquisition of high-level performance in sport validated by Leite, Baker, and Sampaio ${ }^{40}$, supported on the Côté and collaborators $^{39}$ assumptions about general issues related to experiences across sports career. Each participant completed a questionnaire designed to gather qualitative and quantitative information about their previous sports experiences under supervision. The researchers provided a brief explanation of the questionnaire and its completion was designed to take 30 to 60 minutes, according to the level of the athlete, in a quiet environment. The questionnaire was intended to obtain detailed information regarding, i) main sport starting age: age at starting track and field practice; ii) Age of sports initiation: the age of beginning and cessation of practice involved in other sports; iii) specialization age: age at exclusive specialization in track and field; iv) number and amount of time 
spent in unstructured activities such as, playing street football or spontaneous practice; v) number and amount of time spent in structured activities or other sports (formal adult-led sports activities that include all kinds of organized training), and vi) type of structured activities taking into consideration individual, collective and combined sports in a year-by-year description. Following this procedure, a detailed examination of the participants' sports career was obtained considering the DMSP guidelines, as athletes progress through the sampling stage (6-12 years old); specialising stage (13-15 years), and investment stage (16-19 years) $)^{41}$.

\section{Statistical analysis}

The Kolmogorov-Smirnov test was used to verify the normal distribution of variables. The $t$-test was applied to compare groups with normal distribution and the MannWhitney test was used with a non-normal distribution of the variables. Measurements with categorical variables (presented in Table 1) were expressed as percentages (\%) and analysed using the chi-square test $\left(\chi^{2}\right)$. All data were analysed with the statistical package SPSS for Windows, version 21 (SPSS Inc., Chicago, IL). The level of statistical significance was set at $p<0.05$.

\section{Results}

Descriptive statistics for the track and field and age of sports initiation, specialization age, years and amount of practice in track and field, other sports, and unstructured activities are presented in Table 1. Regarding the age of sports initiation, track and field starting age, and specialization age, no differences were found between the expert and non-expert groups. However, the Mann-Whitney test results demonstrated significant differences in the number of years committed with track and field $(\mathrm{U}=251.000$, $p<0.01$ ) for the expert group, and, consequently, the number of total hours spent on the track and field was also higher in this group $(\mathrm{U}=212.500, p<0.01)$. In addition, the previous trend was similar regarding the unstructured activities analysis, since the expert group spent more years in these type of activities $(\mathrm{U}=284.500, p<0.05)$. These results reveal that expert athletes invest more years and time in the track and field, as well as, spent more years involved in unstructured activities. Despite the lack of statistically significant results, the total number of hours spent in unstructured activities disclose a disparity between both groups, in which, the expert athletes largely accumulated more hours.

Descriptive statistics, for the type and number of non-specific and unstructured activities practiced during the sports career, are presented in Table 2. Despite the lack of statistically significant differences in the type and number of other sports practiced by the expert and non-expert athletes, a significant association $\left(\chi^{2}=27.131, p<0.01\right)$ was found between the number of unstructured activities practiced and an expert performance attainment.

\section{Discussion and Conclusions}

This study aimed to characterize the developmental pathway of Portuguese expert track and field athletes considering the quantity and type of structured and unstructured activities. Results showed that expert athletes practice more years and dedicate more hours to track and field training, as well as spent more years practicing a higher number of unstructured activities comparatively to the non-experts' counterparts.

Analysis of age structure of the track and field career and volume of activity types among expert and non-expert revealed that the sport starting age was around the age of 10 , and they started to practice track and field when they were 14 years old. Furthermore, both groups specialized in track and field at 17 . This is consistent with the recent Gullich's ${ }^{42}$ study, which revealed that the German expert track and field pathway is characterized by an early start in other sports, at age of 9 , in track and field, at age of 10 , with a specialization at age of 16 . Considering the practice

Table 1 - Descriptive and inferential statistics for the sport career milestones (mean, SD, minimum and maximum in years of age) for the expert and nonexpert track and field athletes.

\begin{tabular}{lcccc}
\hline Variables & Expert $(\mathbf{n}=\mathbf{2 4}) \mathbf{( M} \pm \mathbf{S D})$ & Non-Expert $(\mathbf{n}=\mathbf{3 5}) \mathbf{( M} \pm \mathbf{S D})$ & $\boldsymbol{p}$ & test \\
\hline Sport starting age & $10.13 \pm 4.32[5-18]$ & $11.09 \pm 4.20[5-21]$ & 0.397 & $\mathrm{t}=-0.853$ \\
Main sport starting age & $14.08 \pm 2.62[8-19]$ & $14.51 \pm 2.94[7-21]$ & 0.566 & $\mathrm{t}=-0.577$ \\
Specialization age & $17.29 \pm 2.24[13-21]$ & $16.66 \pm 1.70[14-21]$ & 0.220 & $\mathrm{t}=1.239$ \\
Years in the specific sport & $7.58 \pm 3.17[3-18]$ & $5.51 \pm 2.20[2-10]$ & $0.009^{*}$ & $\mathrm{U}=251.000$ \\
Total hours in the main sport & $6383.50 \pm 4103.90[2250-20328]$ & $3484.44 \pm 1743.11[768-7056]$ & $0.001^{*}$ & $\mathrm{U}=212.500$ \\
Years practicing non-specific sports & $7.26 \pm 3.94[1-16]$ & $6.97 \pm 3.13[1-13]$ & 0.755 & $\mathrm{t}=0.313$ \\
Total hours of non-specific sports & $2285.35 \pm 1611.29[63-5964]$ & $2438.48 \pm 1665.78[126-7602]$ & 0.727 & $\mathrm{t}=-0.351$ \\
Years of unstructured activities & $7.71 \pm 3.84[4-21]$ & $5.72 \pm 3.24[1-13]$ & $0.035^{*}$ & $\mathrm{U}=284.500$ \\
Total hours in unstructured activities & $3451.04 \pm 3992.32[300-15050]$ & $1872.00 \pm 1576.32[150-7500]$ & 0.142 & $\mathrm{U}=325.500$ \\
\hline
\end{tabular}

${ }^{*}$ Significant differences at $p<0.05$. 
Table 2 - Descriptive and inferential statistics for type and number of practice sports (frequency and \%) for the expert and non-expert track and field athletes.

\begin{tabular}{|c|c|c|c|c|c|}
\hline Variables & & Expert $(n=24)$ Freq. $(\%)$ & Non-Expert $(n=35)$ Freq. $(\%)$ & $p$ & $\chi^{2}$ \\
\hline & Individual & $12(50)$ & $15(46.9)$ & & 0.927 \\
\hline \multirow[t]{3}{*}{ Types of non-specific sports } & Group & $2(8.3)$ & $1(3.1)$ & 0.629 & \\
\hline & Combined & $10(41.7)$ & $16(50)$ & & \\
\hline & 0 & $0(0)$ & $3(8.6)$ & & 3.450 \\
\hline \multirow[t]{4}{*}{ Number of non-specific sports } & 1 & $5(20.8)$ & $9(25.7)$ & 0.327 & \\
\hline & 2 & $8(33.3)$ & $13(37.1)$ & & \\
\hline & $>3$ & $11(45.8)$ & $10(28.6)$ & & \\
\hline & 0 & $0(0)$ & $14(40)$ & & 27.131 \\
\hline \multirow[t]{3}{*}{ Number of unstructured activities } & 1 & $4(16.7)$ & $13(37.1)$ & $0.000^{*}$ & \\
\hline & 2 & $11(45.8)$ & $8(22.9)$ & & \\
\hline & $>3$ & $9(37.5)$ & $0(0)$ & & \\
\hline
\end{tabular}

${ }^{*}$ Significant differences at $p<0.05$.

of additional sports between expert and non-expert, the results of the Portuguese athletes were quite similar, since the experts practiced other sports for 7 years and accumulated around 2,400 hours of experience. In fact, they also practiced their main sport for several years, as well as unstructured activities. However, the accumulated hours were distinct between experts (track and field: 6.300 hours; unstructured: 3.400 hours) and non-experts (track and field: 3.400 hours; unstructured: 1.800 hours) groups. Therefore, the analysis clearly showed that the track and field athletes had an early diversified type of sport involvement with greater participation in unstructured activities. Similar findings were found by Huxley and collaborators $^{43}$, confirming that most track and field athletes had a diversified path without specialized in intense training until the 17 years old (investment stage). These findings provide further support to the DMSP model recommendation, taking into consideration the commitment with several sports sustained upon unstructured activities during the early years ${ }^{11,12,41}$. In fact, substantial literature claims that an early diversification is a suitable pathway to excel at higher levels of performance ${ }^{44-46}$. The commitment to an early diversification, commonly supported in unstructured activities, is typically connected to several beneficial outcomes, related to the boost of physical literacy (fundamental movements), where important athletic skills such as running, jumping, and throwing are stressed and, consequently, it is associated with a prolonged engagement in sports practice. This type of enrichment environment also fosters intrinsic motivation for later investment in the track and field with more structured requirements. Moreover, it also favours the perceptualmotor skills, physical conditioning, psychological, motor, and behaviour transfer, and reduces susceptibility to overuse injury ${ }^{1,29,36,37}$.

The number and years committed with unstructured activities emerged as a key factor, which usually distin- guishes the pathway between experts and non-expert track and field athletes as demonstrated in the Huxley and collaborators $^{43,47}$ studies. Both recommended that early diversification leads to greater success and longevity of the athletes. As previously mentioned, unstructured activities provide more opportunities to learn since children are completely free to explore the surrounding environment $^{3,12,14,15,28}$. Usually, this type of activity allows for children to play with greater skill and older peers, which may act as important role models ${ }^{21}$. In an attempt to promote such diversified environments, a recent study conducted by Cumming and collaborators ${ }^{48}$ analysed children's experience participating in a bio-banded tournament. While the youngest ones emphasized the physical effort and the necessity to constantly adapt their technique and tactics to overcome their opponents, the oldest highlighted the opportunity to explore their skills; nevertheless, all age groups described it is as an extremely positive experience. This exposure provides several experiences and stimuli for children, allowing them to adapt to unpredictable situations in a range of different environments $^{22,49,50}$. In the Coutinho and collaborators study $^{21}$, several expert volleyball players were submitted to an extensive interview regarding previous sports experiences, and they highlighted the importance of unstructured activities to develop physical, technical, tactical, cognitive, and emotional skills throughout their careers. In this line of reasoning, the current findings demonstrate that the majority of track and field expert athletes were committed to more than three or with at least two unstructured activities, while the non-expert athletes were mostly dedicated to none or only one activity. According to social learning theory ${ }^{51}$, children's first experiences in the sport will later shape the type of commitment in a long-term perspective. Considering the benefits of unstructured activities for the athlete's development, sports policies and stakeholders should be aware and 
adopt proper strategies to foster these experiences during the early years providing better facilities and equipment's in outdoor spaces where children can play safely, as well as increase the awareness of coaches, teachers, and parents about the related benefits.

Additionally, the expert track and field athletes dedicated more time to their specialization domain when compared to non-expert athletes. These results clearly demonstrate that expert players can attain higher levels of performance with 6,000 hours of practice, which are consistent with current literature ${ }^{6,7,11,20,40}$. Furthermore, these findings indicate a relationship between sport specific practice and expertise attainment ${ }^{7,10,20,33}$. Recent studies emphasize the importance of practice quality over quantity since during the early years the hours necessary to attain expertise can be accumulated in non-specific sports and unstructured activities, suggesting a functional role in the developmental path. Despite both groups corresponding to the trajectory of early diversification, the expert athletes also accumulated more hours in a specific practice. However, these results should be interpreted with caution since the expert group is older than the non-experts, possibly they are still progressing. In this vein, coaches should promote a diversified path, favouring the unstructured activities during the first phases, and, later on, move towards more structured and specific practices.

\section{Study limitations}

Nevertheless, a limitation of this study is related to the information being gathered through retrospective methodologies, since it only provides a rough explanation of athletes' path trajectory and the recall is associated with a few imprecisions ${ }^{39}$. To reduce the retrospective bias, the information obtained should be triangulated with coaches' and parents' statements, and also repeating the questionnaire at different periods to obtain a more accurate data analysis. Otherwise, recent research has highlighted the importance of a contextual analysis towards examining the athletes' microstructure of practice and other relevant factors (i.e., coaches and teammates' behaviours), that can affect the sport performance ${ }^{21}$. The examination of the developmental context encompasses a more holistic and sustainable approach. In forthcoming studies, it would be important to address the specific impact of unstructured activities on athletes' performance by obtaining detailed information on this type of activities.

\section{Practical application}

From a practical perspective, physical education teachers, coaches, parents, and sport system should provide, during the early years, enrichment environments that promote interaction of unstructured activities with specific practice in order to facilitate the long-term attainment of expertise. These findings reinforced the theoretical assumptions that diversification may lead to several advantages in later sports performance and contribute to the understanding of expert Portuguese track and field athletes' developmental pathway. Further, also may act as a clarification on the sport pathway that should be implemented and used as a recommendation to sustain the athlete's practice.

\section{Acknowledgments}

The authors would like to express their heartfelt appreciation to the following students: André Teixeira, Bernarda Santos, Claudia Faria, and Diogo Ribeiro, for their aid in the data collection process.

\section{References}

1. Lloyd R, Oliver J, Faigenbaum A, Howard R, De Ste Croix M, Williams, et al. Long-term athletic development - part 1: A pathway for all youth. J Strength Cond Res. 2015;29 (5):1439-50. Doi: 10.1519/JSC.0000000000000756.

2. Lloyd R, Oliver J, Faigenbaum A, Howard R, De Ste Croix M, Williams, et al. Long-term athletic development, part 2: Barriers to success and potential solutions. J Strength Cond Res. 2015;29(5):1451-64. Doi: 10.1519/01.JSC.0000465424.75389 .56

3. Collins D, Macnamara R, Mccarthy N. Putting the bumps in the rocky road: Optimizing the pathway to excellence. Front Psychol. 2016;7:1482. Doi: 0.3389/fpsyg.2016.01482

4. Rees T, Hardy L, Güllich A, Abernethy B, Côté, J, Woodman $\mathrm{T}$, et al. The great British medalists project: A review of current knowledge on the development of the world's best sporting talent. Sports Med. 2016; 46(8):1041-58. Doi: 10.1007/s40279-016-0476-2.

5. Swann C, Moran A, Piggot D. Defining elite athletes: Issues in the study of expert performance in sport psychology. Psych Sport Exer. 2015;16:3-14. Doi: 10.1016/j.psychsport.2014.07.004

6. Baker J, Côté J, Abernethy B. Learning from the experts: practice activities of expert decision-makers in sport Res Q Exercise Sport. 2003;74:342-7. Doi: 10.1080/ 02701367.2003.10609101

7. Baker J, Côté J, Deakin J. Expertise in ultra-endurance triathletes early sport involvement, training structure, and the theory of deliberate practice. J Appl Sport Psychol. 2005; 17:64-78. Doi: 10.1080/10413200590907577

8. Coutinho P, Mesquita I, Fonseca A. Talent development in sport: A critical review of pathways to expert performance. Int J Sports Sci Coach. 2016;11(2):279-93. Doi: 10.1177/ 1747954116637499

9. Baker J. Early specialization in youth sport: A requirement for adult expertise? High Abil Stud. 2003; 14(1):85-94. Doi 10.1080/13598130304091

10. Baker J, Horton S, Robertson-Wilson J, Wall M. Nurturing sport expertise: Factors influencing the development of elite athlete. J Sports Sci Med. 2003;2(1):1-7.

11. Côté J, Baker J, Abernethy B. From play to practice: a developmental framework for the acquisition of expertise in team sport. In: Expert performance in sports: Advances in 
research on sport expertise. Champaign, IL: Human Kinetics; 2003. p. 89-113.

12. Côté J, Baker J, Abernethy B. Practice and play in the development of sport expertise. In: Handbook of sport psychology. Hoboken, Wiley; 2007. p.184-202.

13. Côté J, Horton S, Macdonald D, Wilkes S. The benefits of sampling sports during childhood. Phy Health Edu J. 2009;74(4):6-11.

14. Côté J, Lidor R, Hackfort D. ISSP position stand: To sample or to specialize? Seven postulates about youth sport activities that lead to continued participation and elite performance. Int J Sport Exerc Psychol. 2009;7(1):7-17. Doi: 10.1080/1612197X.2009.9671889

15. Côté J, Erickson K. Diversification and deliberate play during the sampling years. In: Routledge handbook of sport expertise. London, Routledge; 2015. p.305-16.

16. Memmert D, Baker J, Bertsch C. Play and practice in the development of sport-specific creativity in team ball sports. High Abil Stud. 2010; 21(1):3-18. Doi: 10.1080/ 13598139.2010.488083

17. Santos S, Memmert D, Sampaio J, Leite N. The spawns of creative behaviour in team sports: a creativity developmental framework. Front Psychol. 2016;7:1282. Doi: 10.3389/fpsyg.2016.01282

18. Santos S, Coutinho D, Gonçalves B, Schölhorn W, Sampaio J, Leite N. Differential learning as a key training approach to improve creative and tactical behavior in youth football players. Res Q Exercise Sport. 2018;89(1):11-24. Doi: 10.1080/02701367.2017.1412063

19. Maxwell J, Masters R, Eves, F. From novice to know-how: A longitudinal study of implicit motor learning. J Sports Sci. 2000;18:111-20. Doi: 10.1080/026404100365180

20. Berry J, Abernethy B, Côté J. The contribution of structured activity and deliberate play to the development of expert perceptual and decision-making skill. J Sport Exerc Psychol. 2008;30:685-708.

21. Coutinho P, Mesquita I, Davids K, Fonseca A, Côté J. How structured and unstructured sport activities aid the development of expertise in volleyball players. Psychol Sport Exerc. 2016; 25:51-9. Doi: 10.1016/j.psychsport.2016.04.004

22. Côté J, Erickson K, Abernethy B. Play and practice during childhood. In: Conditions of children's talent development in sport. Morgantown, WV: FIT, 2013. p. 9-20.

23. Leite N, Santos S, Sampaio J, Gómez M. The path to expertise in Portuguese and USA basketball players. Kinesiology. 2013;45(2):194-202.

24. Santos S, Jiménez S, Sampaio J, Leite N. Effects of the Skills4Genius sports-based training program in creative behavior, PloS One. 2017;12(2):e0172520. Doi: 10.1371/ journal.pone.0172520

25. Abernethy B, Baker J, Côté J. Transfer of pattern recall skills may contribute to the development of sport expertise. Appl Cogn Psychol. 2005;19:705-18. Doi 10.1002/acp.1102

26. Macnamara Á, Collins D. Second chances: Investigating athletes' experiences of talent transfer. PloS One. 2015;10 (11):e0143592. Doi: 10.1371/journal.pone.0143592

27. Santos S, Mateus N, Gonçalves B, Silva A, Sampaio J, Leite $\mathrm{N}$. The influence of previous sport experiences in transfer of behaviour patterns among team sports. Rev Psicol Deporte. 2016;24(1):73-6.

28. Santos S, Mateus N, Sampaio J, Leite N. Do previous sport experiences determine the effect of an enrichment training program in basketball skills? J Sports Sci. 2016;35 (17):1759-67. Doi: 10.1080/02640414.2016.1236206

29. Güllich A. International medallists' and non-medallists' developmental sport activities - A matched-pairs analysis. J Sports Sci. 2016;35(23):2281-8. Doi: 10.1080/ 02640414.2016 .1265662

30. Güllich A, Emrich E. Considering long-term sustainability in the development of world-class success. Eur J Sport Sci. 2014;14(S1):383-97. Doi 10.1080/17461391.2012.706320

31. Macnamara Á, Collins D, Giblin S. Just let them play? Deliberate preparation as the most appropriate foundation for lifelong physical activity. Front Psychol. 2015;6:1548. Doi: 10.3389/fpsyg.2015.01548

32. LaPradre R, Agel J, Baker J, Brenner J, Cordasco F, Côté J, et al. AOSSM early sport specialization consensus statement. Orthop J Sports Med. 2016;8(1):65-73. Doi: 10.1177/ 2325967116644241

33. Feeley B, Agel J, LaPrade F. When is it too early for singlesport specialization? Am J Sports Med. 2016;44(1): 234-41. Doi: 10.1177/0363546515576899

34. Smith A, Alleyne J, Pitsiladis Y, Schneider C, Kenihan M, Constatinou D, Webborn N. Early sports specialization: An international perspective. Curr Sports Med Rep. 2017;16 (6):439-42.

35. Waldron S, Defreese J. Register-Mihalik J, Pietrosimone Barczak. The costs and benefits of early sport specialization: A critical review of literature. Quest. 2020;(72 (1):1-18. Doi: 10.1080/00336297.2019.1580205

36. Myer D, Jayanthi N, Difiori P, Faigenbaum D. Kiefer W, Logerstedt D, et al. Sports Specialization, Part I: Does early sports specialization increase negative outcomes and reduce the opportunity for success in young athletes? Eur J Sports Sci. 2014;14(supp11): S383-S397. Doi: 10.1177/ 1941738115598747

37. Myer D, Jayanthi N, Difiori P, Faigenbaum D, Kiefer W, Logerstedt D, et al. Sports Specialization, Part II: Alternative solutions to early sport specialization in youth athletes. Sports Health. 2015;7(5):437-42. Doi: 10.1177/ 1941738115614811

38. European Athletics Clubs System and Youth Survey Report. Youth activities report. European Athletics. www.europeanathletics.org/mm/Document/Corporate/Whatwedo/01/28/ 01/18/European_Athletics_Report_Part1_Neutral.pdf, 2016.

39. Côté J, Ericsson A, Law M. Tracing the development of athletes using retrospective interview methods: a proposed interview and validation procedure for reported information. J Appl Sport Psychol. 2005;17:1-19. Doi: 10.1080/ 10413200590907531

40. Leite N, Baker J, Sampaio J. Paths to expertise in Portuguese national team athletes. J Sports Sci Med 2009;8 (4):560-6.

41. Côté J, Vierimaa M. The developmental model of sport participation: 15 years after its first conceptualization. Sci Sport. 2014;S63-S69. Doi: 10.1016/j.scispo.2014.08.133 
42. Güllich A. Sport-specific and non-specific practice of strong and weak responders in junior and senior elite athletics - A matched-pairs analysis. J Sports Sci. 2018;36(19):1-9. Doi: 10.1080/02640414.2018.1449089

43. Huxley D, O'Connor D, Bennie A. Olympic and World Championship track and eld athletes' experiences during the specialising and investment stages of development: a qualitative study with Australian male and female representatives. Qual Res Sport, Exer Health. 2017;10(2):256-72.

44. Leite N, Baker J, Sampaio J. Paths to expertise in Portuguese national team athletes. J Sports Sci Med. 2009;8 (4):560-6.

45. Serrano J, Santos S, Sampaio J, Leite N. Initiation, early sport involvement and specialization in futsal training in Portugal. Motriz: J. Phys. Ed. 2013;19(1):99-113. Doi:10.1590/s1980-65742013000100010

46. Moesch K, Elbe AM, Hauge ML, Wikman JM. Late specialization: The key to success in centimeters, grams, or seconds (cgs) sports. Scand J Med Sci Sports. 2011;21(6):28290. Doi: $10.1111 /$ j. 1600-0838.2010.01280

47. Huxley D, O'Connor D, Larkin P. The pathway to the top: Key factors and influences in the development of Australian Olympic and World Championship track and field athletes. Sport Sci Coach. 2017;12(2).

48. Cumming P, Brown J, Mitchell S, Brunce J, Hunt D, Hedges $\mathrm{C}$, et al. Premier League academy soccer players' experiences of competing in a tournament bio-banded for biological maturation. J Sports Sci. 2017;(19):1-9. Doi: 10.1080/ 02640414.2017.1340656.
49. Greco P, Memmert D, Morales JC. The effect of deliberate play on tactical performance in basketball. Percept Mot Skills. 2010,110(3):849-56. Doi: 10.2466/pms.110.3.849856

50. Mateus M, Santos S, Vaz L, Gomes I, Leite N. The effect of a physical literacy and differential learning program in motor, technical and tactical basketball skills. Rev Psicol Deporte. 2016;24(1):73-6.

51. Bandura A. Social-learning theory of identificatory processes. In D. A. Goslin (Ed.), Handbook of Socialization Theory and Research, Chicago, IL: Rand McNally \& Company, 1969. p. 213-62.

\section{Corresponding author}

Sara Santos, Rua dos 3 Lagares, lote $1,5^{\circ}$ drt. Frente, Universidade de Trás-os-Montes e Alto Douro, Vila Real, Portugal.

E-mail: sarasantos_8@hotmail.com or sdlsantos@utad.pt.

Manuscript received on February 22, 2020

Manuscript accepted on May 11, 2020

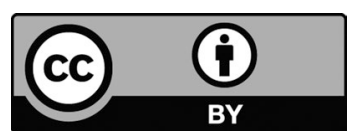

Motriz. The Journal of Physical Education. UNESP. Rio Claro, SP, Brazil - eISSN: 1980-6574 - under a license Creative Commons - Version 4.0 